\title{
FORMACIÓN DOCENTE Y REPRESENTACIONES SOBRE SALUD: CAMINOS PARA LA EDUCACIÓN EN SALUD DESDE UNA MIRADA CRÍTICA
}

RESUMEN: Con el objetivo de realizar un aporte a la formación docente, presentamos un análisis de representaciones sobre salud a partir de definiciones y producciones gráficas en el marco de una experiencia pedagógica para docentes en ejercicio del nivel inicial, realizada entre 2012 y 2014. Las definiciones permitieron reconocer las ontologías subyacentes, mientras que las producciones gráficas desplegaron variados componentes y dimensiones, enriqueciendo a las definiciones. Identificamos una lectura de la salud centrada en el individuo, que relacionamos con categorías de trabajos anteriores como la salud como estilo de vida, la salud como equilibrio y el enfoque educativo comportamental. La reflexión crítica respecto de las prácticas asociadas a esta mirada fue, en nuestra experiencia, una de las puertas de entrada para desnaturalizar lo existente y fomentar perspectivas más complejas, multidimensionales y críticas.

Palabras clave: Representaciones sociales. Salud. Formación docente en ejercicio. Educación Infantil.

\section{FORMACִÃO DE PROFESSORES E REPRESENTACִÕES SOBRE SAÚDE: CAMINHOS PARA A EDUCAÇÃO EM SAÚDE DESDE UMA PERSPECTIVA CRÍTICA}

RESUMO: A fim de fazer uma contribuição para a formação de professores, apresentamos uma análise de representações sobre saúde a partir de definições e produções gráficas no âmbito de uma experiência educacional para professores em atividade do nível inicial, realizada entre 2012 e 2014. As definições permitiram-nos reconhecer as ontologias subjacentes, enquanto as produções gráficas mostraram diversos componentes e dimensões, enriquecendo as definições. Identificamos uma leitura da saúde focada no indivíduo, que relacionamos com categorias de trabalhos prévios, como saúde como estilo de vida, saúde como equilíbrio e a abordagem educativa comportamental. A reflexão crítica sobre as práticas associadas a esse olhar foi, na nossa experiência, um dos pontos de partida para desnaturalizar o existente e incentivar perspectivas mais complexas, multidimensionais e críticas. Palavras chave: Representações sociais. Saúde. Formação de professores em exercicio. Educação infantil.
Fernando Garelli*

Adriana Mengascini**

Silvina Cordero***

Ana Dumrauf****

Universidad Nacional de La Plata (UNLP),

Buenos Aires - Argentina.

Grupo de Didáctica de las Ciencias,

IFLYSIB (CONICET-UNLP),

Calle 59 789, La Plata,

Buenos Aires, B1900BTE.

E-mail: < fgarelli@gmail.com >

* *Universidad Nacional de La Plata (UNLP),

Buenos Aires - Argentina.

Universidad Nacional de Luján/ Grupo de Didáctica de las Ciencias, IFLYSIB (CONICET-UNLP)

E-mail: < amengascini@gmail.com>.

* * Universidad Nacional de La Plata (UNLP),

Buenos Aires - Argentina. Grupo de Didáctica de las

Ciencias, IFLYSIB (CONICET-UNLP). E-mail: < cordero@iflysib.unlp.edu.ar >

* * * Universidad Nacional de La Plata (UNLP),

Buenos Aires - Argentina Grupo de Didáctica de las Ciencias, IFLYSIB (CONICET-UNLP).

E-mail: < adumrauf@iflysib.unlp.edu.ar >. 
TEACHER TRAINING AND REPRESENTATIONS OF HEALTH: PATHS FOR HEALTH EDUCATION FROM A CRITICAL PERSPECTIVE

ABSTRACT: Aiming to make a contribution to teacher training, we present an analysis of social representations of health based on definitions and graphic productions in the context of a formation course for in-service kindergarten teachers. Definitions allowed recognition of several underlying ontologies, while graphic productions displayed different components and dimensions, enriching the definitions. Results showed a perspective of health focused on the individual, related to a representation of health as lifestyle, health as balance and a behavioral educational approach. Critical reflections on educational practices and the various dimensions of health were, in our experience, one of the gateways to denature the existing and more complex, multidimensional and critical perspectives for Health Education.

Keywords: Social representations. Health. In-service teacher training. Kindergarten. 


\section{INTRODUCCIÓN}

Numerosas investigaciones sobre formación de docentes en ejercicio plantean la importancia de valorizar los saberes portados por los y las profesoras, íntimamente ligados a sus prácticas educativas (NÓVOA, 2010; VILANOVA ILHA et al., 2014). Los modelos de desarrollo profesional que privilegian la dimensión interactiva/reflexiva constituyen buenas oportunidades para involucrar al profesorado en su propia formación. La implementación de esos modelos formativos implica, necesariamente, nuevos vínculos entre las comunidades de investigación, de formación y docente.

Durante los últimos años hemos sostenido una experiencia de formación de docentes en ejercicio de Educación Inicial ${ }^{1}$ en el contexto del Proyecto "Estudio de Representaciones y Prácticas en la Educación en Ciencias Naturales, Ambiente y Salud"', cuyo principal objetivo es analizar prácticas educativas innovadoras y caracterizar representaciones sociales, respecto de tópicos específicos en diferentes niveles educativos. Esta experiencia estuvo vinculada a temáticas de la salud, desde una perspectiva multidimensional y compleja. En la misma, consideramos a la salud como derecho humano y como construcción social, compleja e histórica, y por lo tanto dinámica, atravesada por diferentes dimensiones (cultural, política, biológica, biomédica, psicológica, ambiental). Si bien existen diversos posicionamientos acerca de este campo (BRESOLIN MARINHO; DA SILVA, 2015), coincidimos con Estermann Meyer et al. (2006), quienes sostienen que la educación en salud sería la instancia, en los ámbitos educativos, de construcción y socialización de conocimientos y prácticas relacionados a los modos con que cada cultura concibe cómo vivir saludablemente (a diferencia de la educación para la salud, de carácter normativo y preventivo). Desde esta postura se entiende que los problemas de salud poseen componentes amplios e interrelacionados, que no pueden ser evaluados y tratados de forma aislada. Se reconoce, así, a la escuela como uno de los escenarios privilegiados para la promoción de la salud de la población (CARTA DE OTTAWA, 1986), uno de cuyos objetivos involucra la lucha por condiciones de igualdad y justicia social (RESTREPO; MÁLAGA, 2001).

El Diseño Curricular del Nivel Inicial de la Provincia de Buenos Aires, Argentina, incluye "El cuidado de la salud y del medio", explicitando la necesidad de tratar estas problemáticas complejas con aportes de las ciencias naturales y sociales. Plantea tener en cuenta para su análisis "diferentes marcos éticos, religiosos y valorativos; diversos sistemas de creencias y costumbres relacionados con la salud; desiguales condiciones socioeconómicas; el conocimiento científico tecnológico disponible, los aspectos normativos y jurídicos" (DGCyE, 2008: 119). Sin embargo, en nuestra experiencia en espacios de formación docente en ejercicio de este nivel, al indagar acerca de las prácticas de enseñanza vinculadas a la salud, hemos identificado que las docentes suelen focalizar en contenidos referidos a la nutrición, los hábitos de conducta - como la higiene personal, bucal y de manos- y la prevención de enfermedades y accidentes. Construidas en torno a conocimientos técnicos, sus propuestas generalmente incluyen la intervención de especialistas y materiales de campañas de difusión, acercándolas a la noción de prevención de la enfermedad más que a la de promoción de la salud. 
Con base en esta caracterización de las prácticas docentes, resulta interesante profundizar en las representaciones sobre salud que les dan sustento. Acordamos con Giordan (1999) en que las representaciones son en sí mismas elementos que constituyen tanto un punto de apoyo necesario, como herramientas de decisión y de integración a partir de las cuales es posible sugerir pistas para orientar las prácticas educativas.

En este trabajo analizamos las representaciones sobre salud de docentes en ejercicio de Nivel Inicial. Este proceso ha tenido tres aproximaciones: la primera, durante el desarrollo del proceso formativo, de manera colaborativa con las docentes participantes a modo de insumo para la reflexión sobre la práctica. En la segunda, realizamos un análisis inicial de las representaciones de los grupos de docentes (GARELLI et al., 2015). Finalmente, en la tercera ampliamos y profundizamos la indagación acerca de los sentidos otorgados a la salud, a través de la inclusión de nuevas informaciones, la identificación y análisis de las dimensiones que la atraviesan y la consideración de dos planos: el ontológico y el de la praxis, basada en nuevas perspectivas teóricas.

En los apartados que siguen, comenzamos por explicitar los marcos teóricos y la perspectiva metodológica utilizados. A continuación, exponemos el análisis del material empírico, constituido por definiciones escritas de Salud y producciones gráficas sobre "estar sano" elaboradas por profesoras de Educación Inicial en actividad. Finalmente, discutimos los resultados a la luz de los marcos teóricos y realizamos algunas reflexiones enfocadas en la formación docente desde la perspectiva crítica.

\section{MARCO TEÓRICO}

El concepto de representación ha sido estudiado desde diferentes campos. En el marco de la psicología cognitiva, alude a un producto de la selección y categorización de información llevada a cabo por los sujetos en la construcción de saberes y en la comprensión de su entorno. En esta actividad, se privilegian ciertas propiedades de los objetos cognoscibles sobre otras, acentuando diferencias y semejanzas. Este filtro obedece a factores inherentes tanto al sujeto como al contexto social (GUICHARD, 1995). El proceso es eminentemente simbólico ya que la representación puede considerarse como una sustitución, aludiendo a una interpretación y conformando un sistema referencial. La representación implica una relación establecida por un individuo que pertenece a un grupo social determinado con una realidad que él mismo interpreta. Es un reflejo tanto del objeto como de la actividad del sujeto que lo conoce: el sujeto es un actor, un constructor (GUICHARD, 1995). Jodelet (1986), desde la psicología social, define las representaciones sociales como imágenes no especulares que implican una relación sujeto-objeto, cargadas de valores y sentidos generados en el seno de distintos grupos sociales. Condensan significados y se constituyen en sistemas de referencia que permiten interpretar y clasificar circunstancias, fenómenos, individuos con los que interactuamos.

Con respecto a la salud, Breilh (2013) la describe como un objeto polisémico, que admite tres planos relacionados entre sí: el ontológico (¿qué es?), 
el epistemológico (¿cómo se la conoce?) y el plano de la praxis (¿cómo se debe intervenir?). En el marco de la epidemiología (que relaciona salud, enfermedad y atención), este autor reconoce distintos modelos utilizados para explicar los procesos de salud a lo largo de la historia (BREILH 2013).

El modelo empírico ecológico de sistemas entiende a la salud como el equilibrio entre sistemas y subsistemas conectados. Se consideran como sistemas básicos el individuo (visto como huésped) con sus características y susceptibilidad propias; los agentes (infecciosos, físicos y químicos) y el medio (físico, biológico y social). Tanto los factores ambientales como las características del individuo permiten definir variables (factores de riesgo) a ser controladas. En este sentido, la salud pública en general, y la educación en salud en particular, poseen una función social específica: prevenir para reducir riesgos. Este modelo empírico ecológico de sistemas ha estado vigente hasta los inicios de este siglo y, aún hoy, es la base de muchas propuestas de educación para la salud (ESTERMANN MEYER et al, 2006). Por otro lado, en el año 2005 la Organización Mundial de la Salud propuso el modelo de determinantes sociales de la salud, que toma en consideración las inequidades generadas por la desigual distribución de dinero, poder y recursos a nivel mundial, nacional y local (OMS, 2014). Los determinantes sociales de la salud pueden clasificarse en estructurales e intermedios. Los primeros se relacionan con la posición socioeconómica, estructura y clase social; nivel educativo, ocupación e ingreso; relaciones de género y de etnia. Están influidos por el contexto sociopolítico (tipo de gobierno, políticas macro-económicas, sociales y públicas, cultura y valores sociales). Los determinantes intermedios se relacionan con las circunstancias materiales, conductas y factores biológicos. En contrapunto, desde el paradigma crítico, se incorporan las nociones de proceso y de lo colectivo. Mientras que el modelo de los determinantes sociales de la salud se enfoca centralmente en procesos individuales y lo social aparece como "variables" externas que inciden en estados patológicos de personas, la epidemiología crítica asume los procesos colectivos como elementos irreductibles a lo individual, y como espacios de intervenciones. En este marco, la salud es un proceso complejo, socialmente determinado. En dicho proceso interactúan los estilos de vida personales y los modos de vida de los grupos socio-culturales, en una sociedad regida por determinados modelos político-económicos. Esta construcción teórica requiere una lectura crítica de la sociedad, de las formas en las que produce o anula la salud y las formas en las que se encara la defensa de la salud y la lucha por una sociedad más justa e igualitaria. En este sentido, las propuestas educativas que asuman a la salud como objeto complejo, social e históricamente construido, necesitan de una mirada multidimensional y crítica de la realidad de los sujetos y de los grupos sociales.

En el plano educativo, a partir del análisis de libros de textos brasileños, Martins, Santos y El-Hani (2012) describen tres tipos de abordaje de la salud: el biomédico, el comportamental y el socioecológico. En el abordaje biomédico, la salud se define en oposición a enfermedad, privilegiando el tratamiento y la cura del cuerpo y excluyendo influencias en niveles diferentes al biológico. El abordaje comportamental pone el foco en comportamientos, hábitos de vida, elecciones conscientes, las relaciones familiares y sociales. Se trata de un enfoque intermedio donde la salud se encuentra entrelazada tanto a capacidades físico-funcionales 
(asociadas al abordaje biomédico), como al bienestar físico y mental de los individuos (asociado al abordaje socioecológico), que busca el cambio comportamental hacia estilos de vida más sanos, dejando de lado dimensiones sociales y ambientales. El abordaje socioecológico, por último, focaliza fuertemente en una visión positiva y colectiva de la salud, entendida como bienestar biopsicosocial y ambiental. Las condiciones de riesgo ambiental: psicológicas, sociales, económicas, biológicas, educativas, culturales, laborales y políticas son las que determinan la salud.

En el campo del estudio de representaciones sociales sobre salud, las categorías clásicas establecidas por Herzlich (1973) han sido ampliadas por Flick (2000), llegando a una tipología con cuatro grupos de representaciones. La primera de éstas, la salud en el vacío, refiere a la salud como ausencia de enfermedad. Los grupos sociales con este tipo de representaciones tienen poca conciencia respecto de la salud y sólo la conceptualizan en oposición a y como ausencia de enfermedad. La segunda, la salud como reserva, refiere a la fuerza y temperamento como defensa frente a la enfermedad: la salud es una característica que se puede tener en diferentes grados, pero no es un estado. La salud como equilibrio es la última de las representaciones descriptas por Herzlich (1973) y refiere a algo que se tiene o no; hay salud cuando existe un equilibrio entre diferentes aspectos de la vida que llevan a estar de buen humor, activo, bien físicamente y en buena relación con los otros. Flick (2000) amplía esta clasificación incluyendo a la salud como estilo de vida, en la que se pone un mayor énfasis en las elecciones individuales, respecto de actividades y nutrición, por ejemplo.

\section{METODOLOGÍA}

Para relevar las representaciones sobre salud se solicitó, al inicio del curso en cada año (2012 a 2014), la redacción grupal de una definición de salud. Luego los mismos grupos debieron realizar una producción gráfica (tipo collage, para lo cual fueron puestas a su disposición variedad de revistas ilustradas de circulación corriente) representando lo que significaran como "estar sano". A través de estos dispositivos se recogió información y se socializaron, en clase, las producciones de 46 cursantes (2012), 66 (2013) y 23 (2014), organizadas en 7, 6 y 5 grupos de trabajo respectivamente, las cuales constituyen el material empírico del presente estudio (en sus dos tipos, definiciones escritas y producciones gráficas). Las docentes participantes en el curso eran profesoras de Educación Inicial en actividad, con distintos grados de experiencia, que concurrían voluntariamente a este espacio de formación. Se desempeñaban en instituciones de gestión pública (y en algunos casos también en otras de gestión privada) en la ciudad de La Plata y localidades aledañas, a las que concurren niños y niñas de condiciones socio-económicas y procedencias culturales diversas.

Algunos interrogantes fueron un punto de partida previo a nuestro análisis de las producciones: ¿Qué dimensiones de la salud aparecen y de qué manera están expresadas? ¿Qué relaciones se plantean entre enfermedad y salud? ¿Aparecen posicionamientos críticos, reconocimiento de las diferencias entre clases sociales/ géneros/etnias, la diversidad, el conflicto, la complejidad? 
El proceso analítico siguió dos líneas desarrolladas de manera sucesiva. En primer lugar, las definiciones escritas fueron sometidas a un análisis de contenido, siguiendo las fases o momentos que plantea Bardin (1977). Una primera fase consistió en un pre-análisis que implicó la realización de lecturas superficiales de las definiciones, a partir de las cuales se comenzaron a identificar categorías generales. Luego se explicitaron supuestos y objetivos de partida, se elaboraron dimensiones y categorías en las que se apoyó la interpretación y se construyó un esquema analítico de representaciones sobre salud. En una segunda fase se puso en práctica lo que el autor denomina "aprovechamiento del material": se trató fundamentalmente de operaciones de codificación, descomposición y enumeración en función del esquema analítico elaborado, a partir del marco teórico de referencia y el pre-análisis. La tercera fase fue de "tratamiento de resultados, inferencia e interpretación", en la cual se elaboraron resultados y conclusiones, articulando con el marco teórico de referencia. Para representar gráficamente la importancia relativa de los términos incluidos en las definiciones, realizamos una "nube de palabras", un "tipo de figura en la cual las palabras más frecuentes de un texto se resaltan al ocupar más lugar en la representación” obteniendo una "forma rápida y visualmente rica” de mostrar los datos (MC NAUGHT Y LAM, 2010). Utilizamos la aplicación $W_{\text {ordle }}^{3}$ e incluimos sustantivos, adjetivos y verbos presentes en las definiciones.

En la segunda línea analítica, se siguió un enfoque semiótico para indagar las producciones gráficas, según los puntos de vista denotativo (tomando los aspectos más objetivos, identificando los objetos y sujetos representados) y connotativo (apuntando a interpretar las significaciones) (REZLER et al, 2009). A través de este análisis, inicialmente identificamos componentes y sus relaciones en las producciones. En cuanto a las categorías, para su descripción y comparación, además de la consideración general recuperada de las definiciones tradicionales de la salud en sus aspectos biológico, psicológico y social, tomamos las tipologías descriptas por Flick (2000) y Martins et al. (2012). Estas categorías fueron articuladas con otras propias y con emergentes del análisis de nuestra información empírica.

Como procedimientos de triangulación se realizaron contrastaciones entre fuentes de información (definiciones y representaciones gráficas) y entre investigadores (autores de este trabajo), revisando y reformulando las interpretaciones hasta la construcción de acuerdos intersubjetivos.

\section{RESULTADOS}

\section{Análisis de las definiciones de salud}

En la primera fase del análisis de las 18 definiciones relevadas, elaboramos un esquema analítico considerando las dimensiones: ontológica (¿qué es la salud?), aspectos involucrados, modos de lograr la salud (¿cómo se logra estar sano?), metas (¿qué se logra con la salud?), sujetos considerados y singularidades. A modo de ejemplo, en la Tabla 1 mostramos el análisis de las definiciones elaboradas por las docentes en 2014 a través de dicho esquema. 


\begin{tabular}{|c|c|c|c|c|c|}
\hline 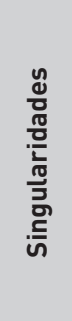 & & 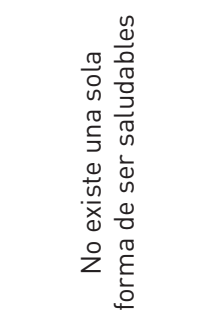 & 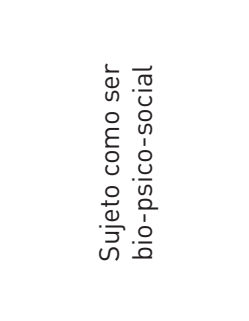 & & \\
\hline 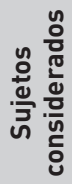 & & 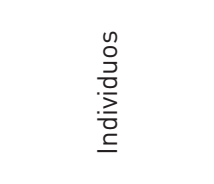 & 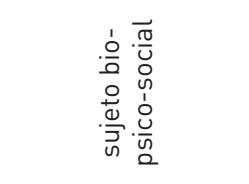 & & \\
\hline 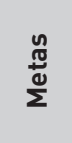 & & 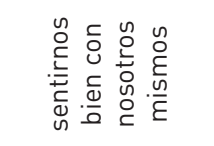 & 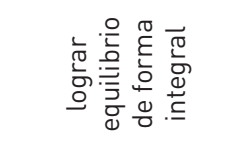 & & $\begin{array}{l}\frac{1}{\pi} \\
\frac{\mathbb{N}}{0} \\
\frac{0}{0} \\
\frac{0}{0}\end{array}$ \\
\hline 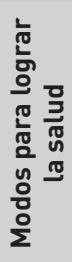 & & 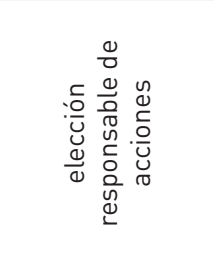 & 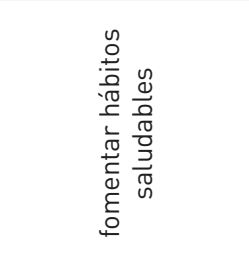 & & 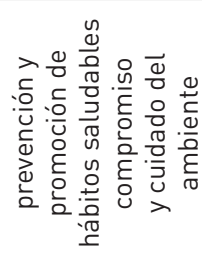 \\
\hline 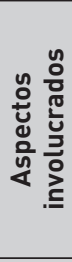 & 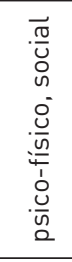 & 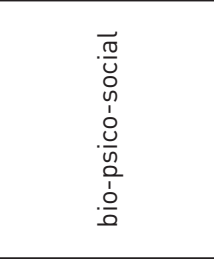 & 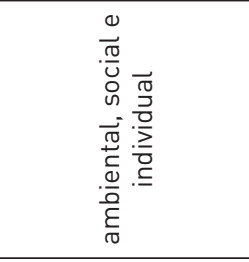 & 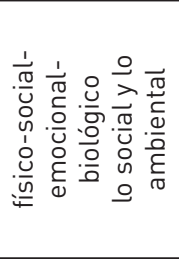 & 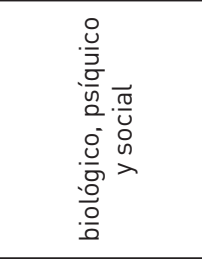 \\
\hline $\begin{array}{l}\frac{\pi}{9} \\
\frac{0}{0} \\
\frac{2}{5}\end{array}$ & 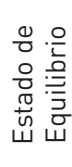 & 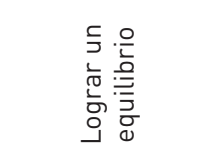 & 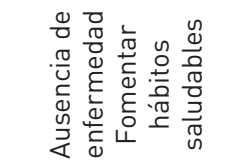 & 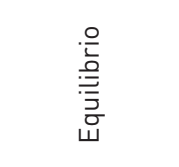 & 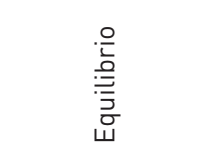 \\
\hline 总 & 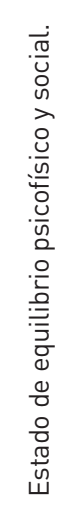 & 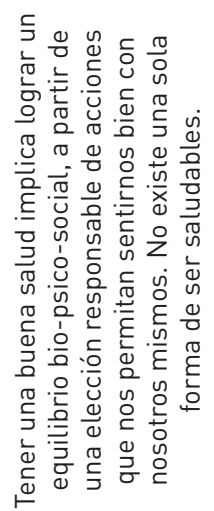 & 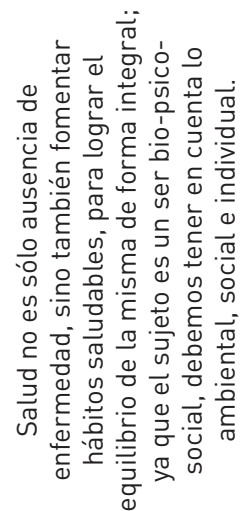 & 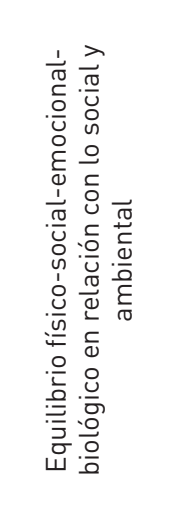 & 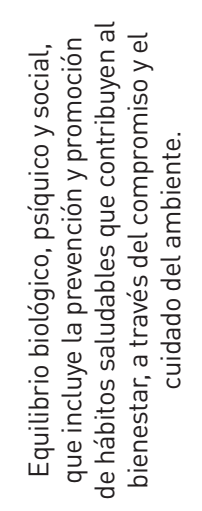 \\
\hline
\end{tabular}


En la dimensión ontológica identificamos 8 maneras diferentes de conceptualizar qué es la salud (algunas de las definiciones incluyeron más de una). La conceptualización

más frecuente (7) fue la de la salud como equilibrio, ya sea como estado o como algo a lograr. Las conceptualizaciones restantes relacionaron a la salud con: ausencia de enfermedad (4); bienestar (4); hábitos saludables (3); cuidado del cuerpo (3); capacidad de adaptación al medio (1); y correcto funcionamiento del organismo (1).

En cuanto a los aspectos involucrados en las definiciones de salud, los más frecuentes fueron los vinculados a lo biológico, lo psicológico y lo social. Otros aspectos mencionados fueron: ambiental, individual, emocional, cuerpo, mente y medio. Éstos darían cuenta de las dimensiones de la salud consideradas en las definiciones.

En algunas definiciones se explicitaron modos para lograr la salud y también metas respecto de ser saludable. Los modos fueron: elección responsable de acciones, lograr el equilibrio, fomentar/ transmitir/ promover hábitos, cuidar y concientizar. Las metas refirieron a: sentirnos bien con nosotros mismos, lograr equilibrio de forma integral, lograr un óptimo estado de equilibrio, bienestar, lograr una mejor calidad de vida, favorecer la integridad física de la comunidad. Esta mención de acciones implicaría considerar dentro de la salud aspectos procesuales. Por su parte, las metas le otorgarían un sentido teleológico a la salud.

Sólo la mitad de las definiciones consideró explícitamente algún sujeto. Predominantemente se apeló a la idea de individuo/ser humano/sujeto/el otro; y, en algunos casos, a sujetos colectivos: población/comunidad/familias/ los demás/las docentes. Por otra parte, en dos casos se incluyeron expresiones relativizando la salud: uno menciona que no existe una única forma de ser saludables; y el otro tiene en cuenta para conceptualizarla a "la población con la que se trabaja”.

Como continuación del análisis realizamos una "nube de palabras" (Figura 1) con sustantivos, adjetivos y verbos, presentes en las definiciones. Para la construcción de esta "nube", fueron consideradas equivalentes las expresiones "bio" y "biológico", y "psico" y "psíquico". 
Figura 1: Nube de palabras construida con los sustantivos, adjetivos y verbos presentes en las definiciones de salud.

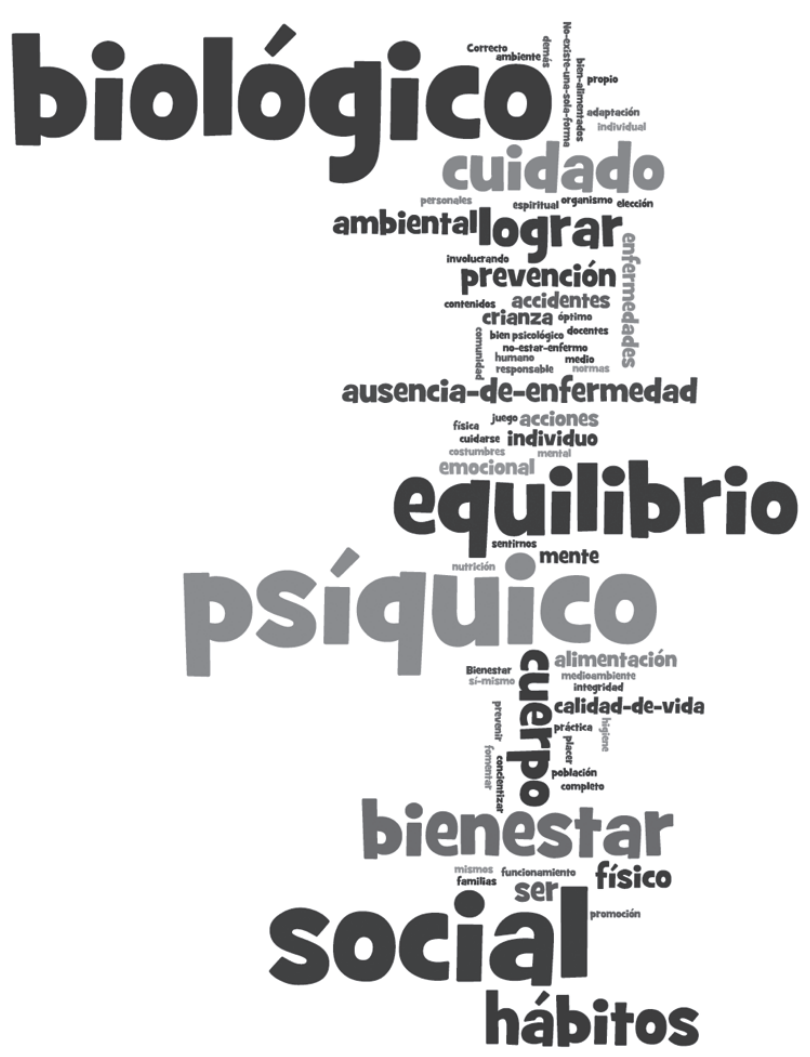

Los términos de la nube que presentan mayor tamaño: "biológico", "psíquico" y "social", pueden vincularse a la definición tradicional de la Organización Mundial de la Salud (1948), de amplia divulgación en el sistema educativo argentino. Si consideramos además los términos de menor tamaño "cuerpo" y "físico", adjudicaríamos mayor énfasis a lo biológico. La noción de "equilibrio", queda también resaltada con este instrumento. Otros términos de importancia serían "bienestar", "hábitos", "cuidado", "lograr". Si bien "social" apareció entre los términos más frecuentes, ninguna de las definiciones sugirió la idea de salud como construcción histórica, dinámica, con discontinuidades o conflictos.

\section{Análisis de las producciones gráficas sobre "estar sano"}

Las 18 producciones gráficas, realizadas por las docentes bajo la consigna: "Estar sano es...", evidenciaron similitudes entre sí, lo cual sugiere una base compartida con relación a esta idea. Permitieron enriquecer, a través de la diversidad de componentes incluidos, los aspectos identificados en las definiciones de salud. 
A partir del análisis denotativo, identificamos componentes y relaciones presentes en las producciones gráficas. A modo de ejemplo, en la Figura 2 incluimos la descripción desde el punto de vista denotativo de una de las producciones gráficas.

Figura 2: Ejemplo de análisis desde el punto de vista denotativo de una producción gráfica

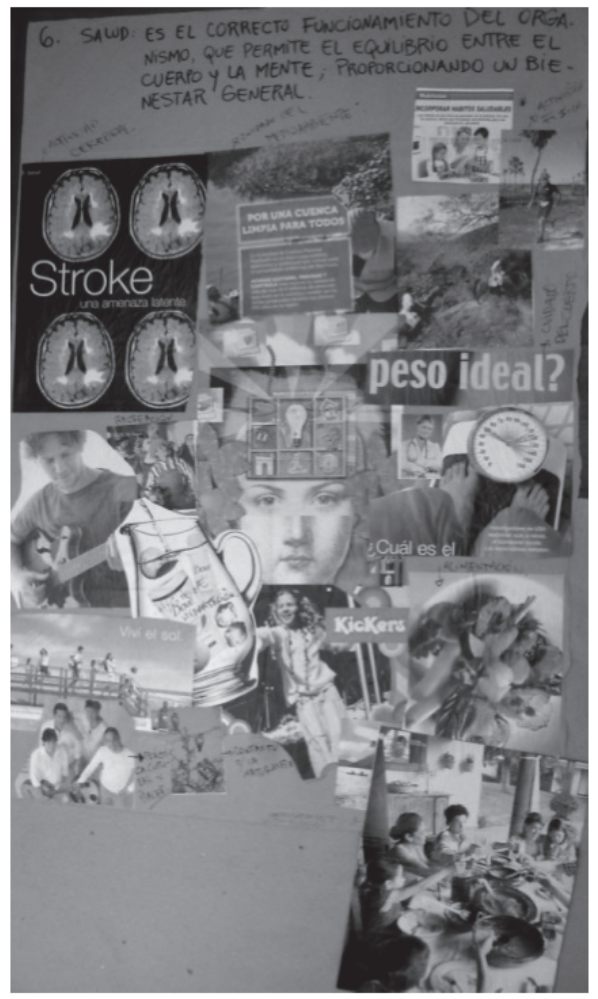

Imágenes:

- Personas limpiando un río

- Mujer con niño y niña preparando una comida

- Hombre corriendo (haciendo deporte)

- Dos hombres andando a caballo

- Cuatro imágenes de tomografias de cerebro

- Médica con estetoscopio

- Pies de una persona pesándose en una balanza

- Hombre tocando una guitarra

- Payasos

- Jarra con agua, dentro del agua hay jabón, desodorante y crema hidratante

- Niña en calesita

- Plato de comida

- Familia sentada a la mesa brindando

- Pájaros en un árbol

- Hombres con instrumentos musicales

- Personas en una pasarela en la playa

- Personas haciendo canotaje

- Rostro de mujer con hojas, un corazón; en la parte de arriba de la cabeza tiene casilleros con una bombilla eléctrica, un bebé, un arco de triunfo, un teléfono, labios, un reloj, dinero, zapatos y bolsa de compras y salen conexiones con cables hacia 4 computadoras (tienen imágenes de bebé, labios y corazones)

Textos: actividad cerebral (en las imágenes de tomografias de cerebro), cuidado del medioambiente (en la imagen de los/as que limpian el río), actividad física (en el que corre), cuidado del cuerpo - peso ideal? (en los pies con la balanza, ambos), incorporar hábitos saludables (mujer con niñas/os cocinando), alimentación (en el plato de comida), higiene hidratación (en la jarra con agua y otras cosas), hábitos culturales que invitan al diálogo (en los/as que están brindando y comiendo guiso), contacto con la naturaleza (en pájaros en el árbol), viví el sol (en imagen de playa), práctica cultural por placer (hombres con instrumentos musicales), recreación (donde están los payasos y el que toca la guitarra).

Definición escrita asociada: Es el correcto funcionamiento del organismo, que permite el equilibrio entre el cuerpo y la mente; proporcionando un bienestar general.

Agrupamos los componentes en 7 dimensiones que caracterizarían el estar sano. Éstas estuvieron basadas en categorías previas (dimensiones cultural, política, biomédica, psicológica, ambiental), redefinidas o construidas a partir de aspectos emergentes. Agregamos como dimensiones emergentes la dimensión socialy la espiritual; y consideramos la conveniencia de discriminar dentro de la dimensión psicológica dos subdimensiones (individual-afectiva e interpersonal). La inclusión de la dimensión social se debió a que las imágenes presentes en las producciones gráficas, que asociamos a esta dimensión, apuntaban a vínculos comunitarios, solidarios, de pertenencia, sin connotar relaciones de poder, desigualdades o conflictos - que, posicionándonos desde una perspectiva crítica, nos habrían permitido vincularlas con la dimensión política. En la Tabla 2 presentamos los componentes asociados a cada dimensión. 
Tabla 2: Componentes y dimensiones identificados en el análisis de las producciones gráficas

\begin{tabular}{|c|c|c|}
\hline \multicolumn{2}{|c|}{ Dimensión } & Componentes \\
\hline \multicolumn{2}{|c|}{ Biomédica } & $\begin{array}{l}\text { alimentos, tensión entre lo rico y lo sano, } \\
\text { deporte, descanso, higiene, médica/o, “agua } \\
\text { pura”, prevención de enfermedades, vacunación, } \\
\text { atención de la enfermedad, influencia de las } \\
\text { emociones, cuidado del cuerpo, enseñanza de } \\
\text { hábitos, información, equilibrio, energía, “dime } \\
\text { qué comes y te diré cómo estás” }\end{array}$ \\
\hline \multirow[t]{2}{*}{ psicológica } & individual-afectiva & $\begin{array}{l}\text { lectura, imaginación, creatividad, desarrollo } \\
\text { intelectual, aprendizaje, sonreír, reír, recreación, } \\
\text { música (personas con instrumentos), relax, jugar, } \\
\text { bailar, psicólogo, contacto con la naturaleza, } \\
\text { personas con mascotas, ocio, felicidad, elegir, } \\
\text { placer, humor, concientización corporal, } \\
\text { autoestima, sueños, cuidado, bienestar, sentir }\end{array}$ \\
\hline & $\begin{array}{l}\text { vínculos } \\
\text { interpersonales }\end{array}$ & $\begin{array}{c}\text { pareja, embarazo, familia, encuentro, amigos, } \\
\text { amor, afecto, jugar, alegría, compartir, cuidado, } \\
\text { amamantamiento, contención }\end{array}$ \\
\hline \multicolumn{2}{|r|}{ Social } & $\begin{array}{l}\text { educación, solidaridad, compromiso con la } \\
\text { comunidad, sentido de pertenencia, compartir, } \\
\text { fiestas, multiactividad de la mujer actual, } \\
\text { inclusión educativa, sociabilizarse, atención a la } \\
\text { diversidad (necesidades especiales) }\end{array}$ \\
\hline \multicolumn{2}{|r|}{ Cultural } & $\begin{array}{l}\text { música (espectáculo), platos de comidas típicas, } \\
\text { "hábitos culturales que invitan al diálogo" }\end{array}$ \\
\hline \multicolumn{2}{|r|}{ Política } & $\begin{array}{l}\text { conflicto social, reclamo docente, campañas de } \\
\text { salud pública, imagen de un campo sembrado y } \\
\text { cosechadora con texto "Boom de la soja" } \\
\text { intervenido con un signo de pregunta }\end{array}$ \\
\hline \multicolumn{2}{|c|}{ Ambiental } & $\begin{array}{l}\text { naturaleza, cuidado del ambiente, ambiente, } \\
\text { naturaleza como recurso }\end{array}$ \\
\hline \multicolumn{2}{|c|}{ Espiritual } & $\begin{array}{c}\text { ermita, prácticas orientales para “estar bien en } \\
\text { cuerpo y alma”, buda }\end{array}$ \\
\hline
\end{tabular}

Como surge de la lectura de la Tabla 2, la dimensión psicológica presentó la mayor diversidad de componentes. Sin embargo, fue la biomédica la de aparición más frecuente. De todos los componentes, los más numerosos estuvieron relacionados con los alimentos y la actividad física. La dimensión espiritual se representó escasamente y la política también apareció en forma débil. Finalmente, la dimensión cultural sólo fue identificada con relación a espectáculos musicales folclóricos y a la promoción de hábitos culturales -explícitamente indicada- a través de comidas típicas. 
Las imágenes de alimentos que aparecieron en las representaciones gráficas incluyeron los considerados, habitualmente, como saludables: frutas, verduras, jugos, pescados, lácteos y, en menor proporción, carnes rojas o aves.

Una de las producciones gráficas presentó una imagen de tensión entre lo bueno y lo rico a través del juego de "tirar de la cuerda": en uno de los extremos de la cuerda aparecían mujeres delgadas (con el rótulo: "bueno”), mientras que, desde el otro extremo se le oponían hombres con sobrepeso (bajo el rótulo: "rico'). Esta imagen estaría evidenciando diferentes estereotipos: por un lado, el vinculado a la tensión entre salud y placer (lo bueno vs lo rico) y, por otro, a diferencias sociales de géneros y sus actitudes con relación a este tema.

La mayoría de las producciones gráficas se inscribió dentro de lo que denominamos Esquema General. El Esquema General incluyó una serie de imágenes y palabras representando los componentes de lo que implica estar sano, con escasa conexión entre sí. En la Figura 3 presentamos una de las producciones que ejemplifica el Esquema General.

Figura 3: Ejemplo de producción gráfica que responde al Esquema General.

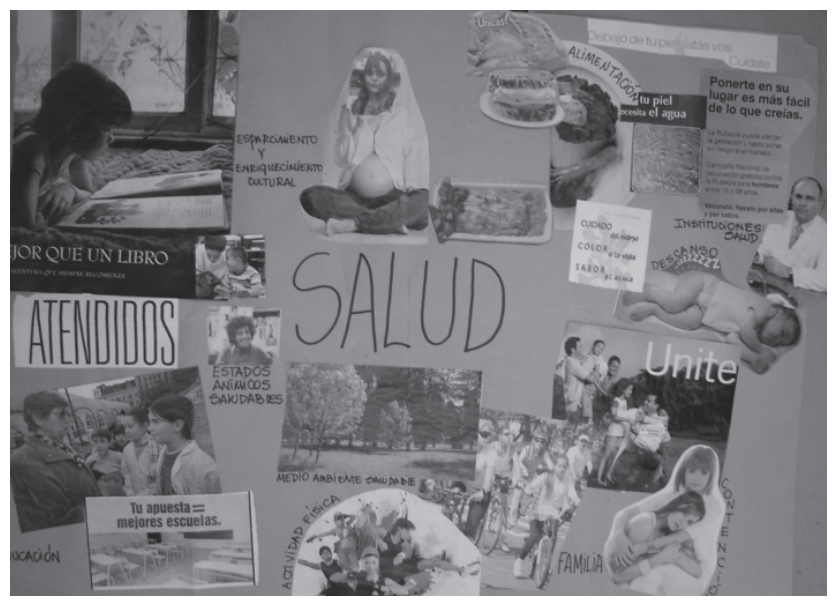

De acuerdo a este Esquema, estar sano implicaría ser una persona activa, que se ocupa de sí misma y mantiene buenas relaciones con quienes la rodean. Esto se expresaría, entonces, tanto en un plano individual (sana sería la persona que se ocupa de realizar ciertas actividades como ejercitarse, comer bien, descansar, relajarse, sonreír, expresarse artísticamente, etc.) como en un plano interpersonal (sano sería tener buenas relaciones con su círculo cercano de familia y amistades). Del total de 18 producciones gráficas, 12 responden a este Esquema.

Otras 5 se diferencian de éstas a partir de mostrar, además de figuras representando lo que estaría dentro de estar sano, otros elementos que quedarían fuera de ese concepto. En la Figura 4 mostramos un caso en el que, además de plantearse esta diferenciación, se señalan gráficamente interacciones entre lo sano y lo no sano. 
Figura 4: Representación gráfica que muestra interacciones entre sano y no sano

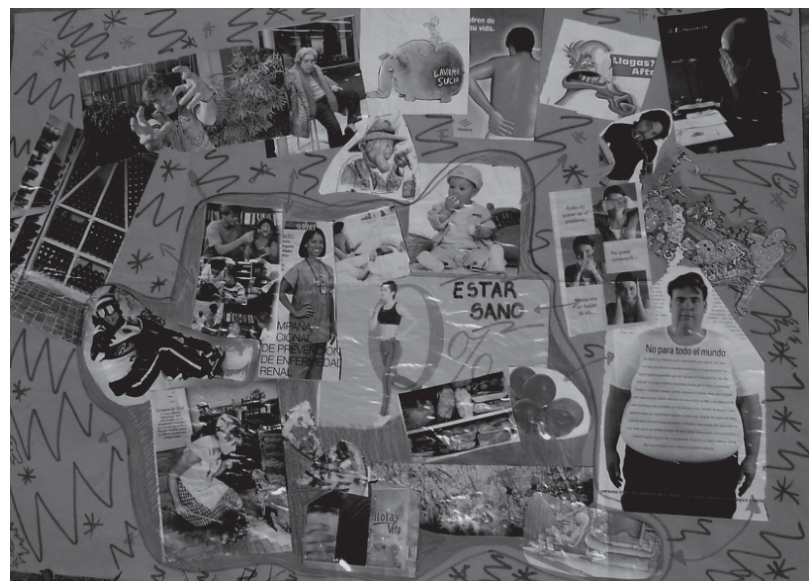

En ésta y en otras 4 producciones se indicó, a veces a través de recursos gráficos interviniendo las imágenes (bandas rojas cruzadas u otras señales de prohibición), aquellos aspectos considerados no sanos: dolor; preocupación; negación (no querer enterarse); suciedad; enfermedad; vejez; enojo; bebidas alcohólicas; cigarrillos; contradicciones de la vida actual. En estos casos, para representar lo sano, se consideró necesario incluir su opuesto, lo cual podría interpretarse como la dificultad para pensar la salud en términos absolutos, es decir sin tener en cuenta elementos valorados como negativos o no saludables.

Por último, una de las producciones representó la figura de un/a equilibrista (Figura 5).

Figura 5: Representación gráfica de "estar sano" como equilibrista

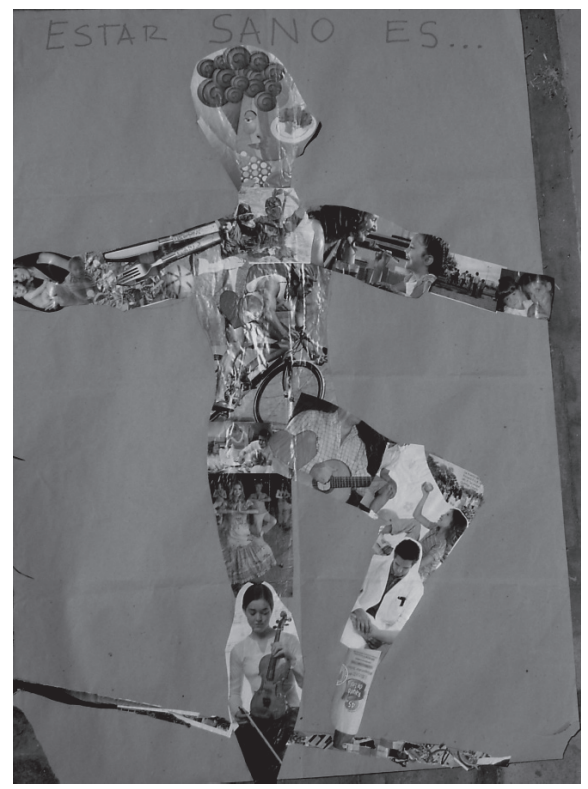


En esta producción se plasmó gráficamente la idea de equilibrio incluyendo componentes similares a los presentados en las del Esquema General, pero adaptándolos a una forma específica. La yuxtaposición de componentes adquiere un sentido particular, un equilibrio que podría perderse (por representar al/la equilibrista sobre una cuerda o vara).

\section{DISCUSIÓN}

Definiciones y producciones gráficas posibilitaron una aproximación a las representaciones de las docentes sobre salud. Las definiciones permitieron una primera caracterización de las ontologías subyacentes, mientras que las producciones gráficas posibilitaron desplegar los diferentes componentes comprendidos en cada dimensión de la salud.

En las producciones gráficas, las representaciones de salud estarían principalmente vinculadas con la categoría estilo de vida presentada por Flick (2000), que incluye tópicos tales como: andar en bicicleta en lugar de conducir automóviles, hacer ejercicios físicos, comer saludablemente, etc. Así, es a partir de lo que cada sujeto hace que logra alcanzar la salud. La única producción gráfica que se apartaría de esta representación sería la del/la equilibrista, que vinculamos con la categoría de salud como equilibrio.

En nuestro análisis de las definiciones, las dimensiones analíticas “ontología” y "aspectos involucrados", estarían relacionadas con el plano ontológico de las representaciones sobre salud. Las "metas" analizadas en las definiciones profundizarían y especificarían los sentidos atribuidos por las docentes en este mismo plano. También las definiciones evidenciarían representaciones de salud como equilibrio y como estilo de vida (a través de la consideración de la ausencia de enfermedad, el bienestar, los hábitos saludables, entre otros).

Podríamos asociar ambas categorías, salud como equilibrio y como estilo de vida, de Flick (2000) con el modelo empírico ecológico de sistemas para interpretar las relaciones salud-enfermedad descripto por Breihl (2013). Acorde con este modelo, el cambio en los estilos de vida reduciría riesgos y prevendría la aparición de enfermedades, asignando responsabilidades al individuo y al entorno más cercano. Los "modos para lograr la salud" que caracterizamos (elección responsable de acciones, fomentar/ transmitir/ promover hábitos, cuidar y concientizar) se vincularían con el plano de la praxis definido por Breihl (2013) y sostendrían las prácticas docentes en el aula. En concordancia con el planteo de este autor (Breihl 2013), el plano ontológico de las representaciones de las docentes se vincularía dialécticamente con sus maneras de conocer y actuar en las aulas. En el mismo sentido, en este plano práxico, las docentes intentarían cambiar conductas y generar "hábitos", definidos desde una perspectiva higienista que pretende ser universal, tal como relevamos en investigaciones previas (CORDERO et al., 2016) y en acuerdo con los enfoques de educación para la salud de abordaje comportamental (BRESOLIN MARINHO: DA SILVA, 2015). Es decir, la búsqueda del cambio de comportamientos hacia estilos de vida más sanos (MARTINS, SANTOS Y EL-HANI, 2012). 
Como ya hemos dicho, comparando ambos tipos de producciones, escritas y gráficas, encontramos que las últimas permitieron desplegar una mayor capacidad expresiva a las docentes y ofrecieron, por lo tanto, lecturas analíticas más ricas. Las dimensiones que, desde nuestro punto de vista, estuvieron escasamente presentes fueron la política y la cultural. La limitada presencia de la dimensión política en la representación social de la salud formaría parte de lo "no pensable" en términos de Bourdieu (1991) contribuyendo a constituir un habitus (coherente con una mirada hegemónica normalizadora) que oculta las relaciones de poder presentes en toda sociedad. Las imágenes asociadas a la dimensión cultural en las producciones gráficas connotarían una concepción restringida de cultura vinculada a lo folclórico o tradicional (a través de las comidas o la música). Paralelamente, la noción de diversidad presente se enfocaría en la atención a las personas con necesidades especiales (en sillas de ruedas, con síndrome de Down, etc), sin considerarse otras diversidades (de etnia o de género, por ejemplo).

La predominancia de la noción de equilibrio en las definiciones, sumada al tipo de imágenes asociables a las dimensiones política, social y cultural estaría dando cuenta de una representación de salud que, si bien presenta algunos indicios procesuales, no respondería a una mirada dialéctica (característica del paradigma crítico).

\section{CONCLUSIONES}

Teniendo en cuenta que el conocimiento de las representaciones sociales constituye un punto de partida importante para la elaboración de proyectos educativos, analizamos en este trabajo aquéllas relacionadas a la salud. Particularizamos en una población de docentes de Nivel Inicial de la ciudad de La Plata (Buenos Aires, Argentina) e intentamos aportar a la formación docente y a la construcción de propuestas didácticas contextualizadas. En ese camino, elaboramos un esquema que involucra una serie de dimensiones analíticas emergentes y que podría ser útil para el análisis de otros casos. Articulamos, asimismo, referencias teóricas procedentes del campo de la psicología social, de la epidemiología y de la educación en salud.

Las representaciones sociales de la salud como estilo de vida y como equilibrio y el enfoque educativo comportamental, que surgen de los resultados que aquí presentamos, evidencian una lectura de la salud centrada en el individuo y atravesada, principalmente, por las dimensiones biomédica y psicológica. Estas representaciones dejan ocultos los procesos colectivos, políticos y culturales y su influencia para la determinación de la salud, en coincidencia con uno de nuestros supuestos de partida al diseñar el proceso de formación docente. La reflexión crítica con relación a aspectos concretos relacionados con las representaciones relevadas (por ejemplo: el acceso a una buena alimentación) fue, en nuestra experiencia (MENGASCINI et al., 2014) -y podría serlo para otras-, una de las puertas de entrada para desnaturalizar lo existente y comenzar a develar esas aristas ocultas de la salud.

Plantear la salud como construcción socio-histórica y derecho humano es convertirla en un objeto complejo. Conocer este objeto complejo, desde una perspectiva crítica, significa, por un lado, comprender diferentes dimensiones que la atraviesan y se entretejen de manera situacional, contextual y dialéctica. Por otro, 
requiere el reconocimiento de sus determinaciones sociales y de la apropiación de conocimientos para la participación. Desde el punto de vista de las prácticas, el abordaje de este objeto complejo exige para las docentes, al menos: ampliar el conocimiento acerca de sus estudiantes, sus historias y modos de vida, el contexto en el que viven y la consideración de las dimensiones socio-culturales, económico- políticas y científica en cada tema a abordar. Esto porque la promoción de la salud que se propone la igualdad y la justicia social adopta modelos epidemiológicos críticos, que consideran la "determinación social" de la salud y la importancia de la participación colectiva.

En síntesis, tanto en la formación docente como en la educación en salud en general, es necesario reconocer la disputa existente en cuanto a "cómo enunciar la salud y cómo actuar" y que "esa disputa obedece a intereses sociales encontrados" (BREIHL, 2013). De acuerdo con Huergo (2001),

Una educación contrahegemónica en salud se inicia precisamente con la desnaturalización de los significados dominantes sobre la salud y los sistemas de salud, historizándolos y desmontándolos, de modo de reconocerlos encarnados en la subjetividad, en las relaciones, en las prácticas, en los saberes y en los procesos individuales y sociales. (HUERGO, 2001: 13)

No es posible producir experiencias innovadoras y críticas en salud si no se crean espacios para cuestionar y autocuestionar los significados hegemónicos "desde los cuales la vida y la experiencia es hablada” (HUERGO, 2001: 13). La explicitación y problematización de las propias representaciones y prácticas es el camino que hemos elegido para construir una educación en salud desde una mirada crítica.

\section{NOTAS}

1 El curso La alimentación en la enseñanza del área El Ambiente Natural y Social en el Nivel Inicial fue ofrecido para docentes en ejercicio de Jardines Maternales y de Infantes (0-5 años), por un equipo interdisciplinario de docentes universitarias, del que participó una capacitadora de la Dirección de Capacitación, Dirección General de Cultura y Educación, Provincia de Buenos Aires, Argentina.

2 PERSPECNAS, acreditado en el Consejo Nacional de Investigaciones Científicas y Técnicas (CONICET) y la Universidad Nacional de La Plata, Argentina.

3 http://wordle.net

\section{REFERENCIAS}

BARDIN, L. Análisis de Contenido (2da ed.). Madrid: Akal, 1977.

BREILH, J. La determinación social de la salud como herramienta de ruptura hacia la nueva salud pública (salud colectiva). Epidemiología crítica latinoamericana: raíces, desarrollos recientes y ruptura metodológica. Revista de la Facultad Nacional de Salud Pública, 31 (supl 1), p. 13-27, 2013.

BRESOLIN MARINHO, J.C.: DA SILVA, J.A. Concepções e implicações da aprendizagem no 
campo da educação em saúde. Revista Ensaio, Belo Horizonte, v.17, n. 2, p. 351-371, maio-ago 2015. BOURDIEU, P. El sentido práctico. Madrid: Taurus, 1991.

CORDERO, S.; MENGASCINI, A.; MENEGAZ, A.; ZUCCHI, M.; DUMRAUF, A. La alimentación desde una perspectiva multidimensional en la formación de docentes en ejercicio. Ciência \& Educação (Bauru), v. 22, n. 1, p. 219-236, 2016.

DIRECCIÓN GENERAL DE CULTURA Y EDUCACIÓN (DGCyE). Diseño curricular para la Educación Inicial. La Plata: Dirección General de Cultura y Educación de la Provincia de Buenos Aires, 2008.

ESTERMANN MEYER, D. E.; FALLEIROS DE MELLO, D.; VALADÃO, M. M.; DE CARVALHO MESQUITA AYRES, J. R. "Você aprende. A gente ensina?” Interrogando relações entre educação e saúde desde a perspectiva da vulnerabilidade. Cadernos de Saúde Pública, v.22, n. 6, p. 1335-1342, 2006.

FLICK, U. Qualitative inquiries into social representations of health. Journal of Health Psychology, v. 5, p. 315-324, 2000.

GÁLVEZ, R.; IRAZOLA, J. El Árbol de la transformación: manual de metodologías participativas para agentes de salud comunitaria. Buenos Aires: Medicusmundi, 2006.

GARELLI, F.; MENGASCINI, A.; CORDERO, S.; DUMRAUF, A. ¿Qué es la salud? Imágenes y representaciones de docentes de Nivel Inicial. In: Encontro Nacional de Pesquisa em Educação em Ciências, 10, 2015, Águas de Lindóia (SP, Brasil). Anais... São Paulo. 2015.

GIORDAN, A. Une didactique pour les sciences expérimentales. París: Editions Belin, 1999. GUICHARD, J. Hábitos, representaciones sociales y categorizaciones. Barcelona: Laertes, 1995. HERZLICH, C. Health and Illness. London: Academic Press, 1973.

HUERGO, J. "Del modelo hegemónico a la intervención contrahegemónica en salud”, II Jornadas Nacionales de Medicina Antropológica, La Plata: UNLP, 2001.

JODELET, D. La representación social: fenómenos, concepto y teoría. En: MOSCOVICI, S. Psicología Social II. Barcelona: Paidós, 1986.

KORNBLIT, A. L.; DIZ, A. M. M. La salud y la enfermedad: aspectos biológicos y sociales. Buenos Aires: Aique, 2000.

MARTINS, L.; SANTOS, G.S.; EL-HANI, C.N. Abordagens de saúde em um livro didático de Biologia largamente utilizado no Ensino médio brasileiro. Investigações em Ensino de Ciências, v. 17, n. 11, p. 249-283, 2012.

MENGASCINI, A.; CORDERO, S.; MENEGAZ, A.; ZUCCHI, M.; DUMRAUF, A. Más allá de la visión escolarizada de alimentación: Resultados de una propuesta de formación en ejercicio con docentes del nivel inicial. In: Encuentro de Didáctica de las Ciencias Experimentales, 26, 2014. Anais... Huelva: Universidad de La Rábida (España), 2014. p 318-326.

MCNAUGHT, C.; LAM, P. Using Wordle as a supplementary research tool. The qualitative report, v. 15, n. 3, p. 630-643, 2010.

MORAGAS, R. Enfoque sociológico de diversas concepciones de salud. Papers: Revista de Sociologia, n. 5, p. 31-54, 1976.

MOSCOVICI, S. Psicología Social II. Barcelona: Paidós, 1986.

ORGANIZACIÓN MUNDIAL DE LA SALUD. Carta de Ottawa para la Promoción de la Salud. 1986. Disponible en: http://www.fmed.uba.ar/depto/toxico1/carta.pdf Acceso en: 15 de diciembre de 2014.

ORGANIZACIÓN MUNDIAL DE LA SALUD. Determinantes sociales de la salud. 2014. Disponible en: http://www.who.int/social_determinants/es/ Acceso en: 20 de agosto de 2014. 
ORGANIZACIÓN MUNDIAL DE LA SALUD. Constitución de la organización Mundial de la Salud. 1948. Disponible en: http://www.who.int/about/mission/es/ Acceso en: 11 de noviembre de 2015.

RESTREPO, H.; MÁLAGA, H. Promoción de la salud: cómo construir vida saludable. Bogotá: Editorial Médica Panamericana, 2001.

REZLER, M.A.; SALVIATO, G.M.; WOSIACKI, S.R. Quando a imagem se torna linguagem de comunicação de estudantes da $5^{a}$ e $6^{a}$ séries do ensino fundamental em Educação Ambiental. Revista Electrónica de Enseñanza de las Ciencias, v. 8, n. 1, p. 304-325, 2009.

VILANOVA ILHA, P.; SANTOS DE LIMA, A.P.; SASTRE ROSSI, D.; ANTUNES SOARES, F.A. Intervenções no ambiente escolar utilizando a promoção da saúde como ferramenta para a melhoria do ensino. Ensaio, v. 16, n. 3, p. 35-53, 2014.

Sumisión en 16/11/15

Aprobación em 03/02/17

\section{Dirección:}

Fernando Garelli

Grupo de Didáctica de las Ciencias, IFLYSIB (CONICET-UNLP), Calle 59 789, La Plata, Buenos Aires, B1900BTE 
